\title{
Simple screening model for identifying the risk of sleep apnea in patients on opioids for chronic pain: an infographic
}

\author{
Rajnish K Gupta (10), ${ }^{1}$ Eric S Schwenk (i) ${ }^{2}$
}

\section{ABSTRACT}

Chronic pain patients taking opioids are at higher risk for obstructive sleep apnea (OSA) than the general population. Fifty million people in the USA have chronic pain and $20 \%$ of these patients are on opioids. Of these chronic pain patients on opioids, 59\% had undiagnosed sleep apnea and 30.8\% of these had severe OSA. A simple OSA screen using the STOP-Bang Questionnaire and resting daytime $\mathrm{SpO}_{2}$ in the clinic can be very sensitive at detecting undiagnosed OSA. Those patients can be sent for definitive polysomnography (sleep study). However, this simple standard screening evaluation is not very specific and many patients without OSA end up receiving a sleep study that is expensive, time consuming and has limited availability. Selvanathan et al propose an additional step to the screening model by adding a home oxygen desaturation test. ${ }^{1}$ With this additional tool, the authors were able to rule out OSA for nearly 38\% more patients than by just doing the STOP-Bang Questionnaire or resting oxygen saturation alone. The addition of home oximetry to detect oxygen desaturation events is a simple and effective way to screen for OSA in this high-risk population while reducing the number of patients without OSA who needed to undergo a sleep study.

${ }^{1}$ Anesthesiology, Vanderbilt University Medical Center, Nashville, Tennessee, USA

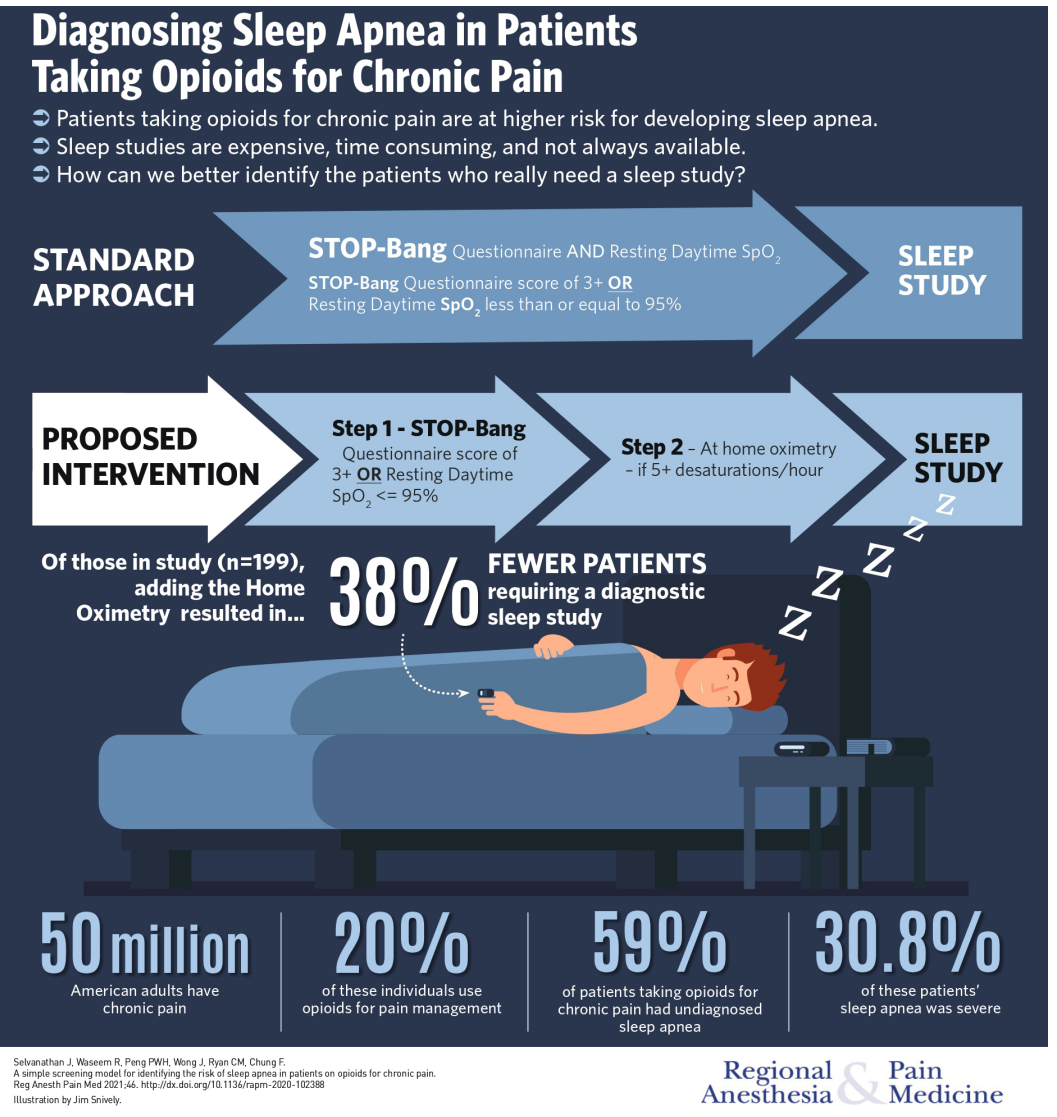

${ }^{2}$ Anesthesiology, Sidney Kimmel Medical College, Thomas Jefferson University, Philadelphia, Pennsylvania, USA

Correspondence to Dr Rajnish K Gupta, Anesthesiology, Vanderbilt University Medical Center, Nashville, Tennessee, USA; raj.gupta@vumc.org

Twitter Rajnish K Gupta @dr_rajgupta and Eric S Schwenk@ESchwenkMD

Acknowledgements The authors would like to acknowledge Jim Snively, artist, of Pittsburgh, Pennsylvania, for creation of this infographic.

Contributors Both authors contributed to the content and editing of the infographic.

Funding The authors have not declared a specific grant for this research from any funding agency in the public, commercial or not-for-profit sectors.

Competing interests Both authors are associate editors for Regional Anesthesia and Pain Medicine. RKG is a board member of the American Society of Regional Anesthesia and Pain Medicine.

Patient consent for publication Not required.

Provenance and peer review Commissioned; internally peer reviewed.

(C) American Society of Regional Anesthesia \& Pain Medicine 2021. No commercial re-use. See rights and permissions. Published by BMJ.

\section{(D) Check for updates}

To cite Gupta RK, Schwenk ES. Reg Anesth Pain Med 2021;46:892.

\section{Received 28 July 2021}

Accepted 29 July 2021

Published Online First 9 August 2021

\section{(S) Linked}

- http://dx.doi.org/10.1136/rapm-2020-102388

Reg Anesth Pain Med 2021:46:892.

doi:10.1136/rapm-2021-103010

ORCID iDs

Rajnish K Gupta http://orcid.org/0000-0003-34014737

Eric S Schwenk http://orcid.org/0000-0003-3464-4149

\section{REFERENCE}

1 Selvanathan J, Waseem R, Peng P. A simple screening model for identifying the risk of sleep apnea in patients on opioids for chronic pain. Reg Anesth Pain Med 2021:46:886-91. 